\title{
Interviewing insights regarding the fatalities inflicted by the 2011 Great East Japan Earthquake
}

\author{
M. Ando ${ }^{1}$, M. Ishida ${ }^{2}$, Y. Hayashi ${ }^{3}$, C. Mizuki ${ }^{4}$, Y. Nishikawa ${ }^{5}$, and Y. Tu ${ }^{1}$ \\ ${ }^{1}$ Institute of Earth Sciences, Academia Sinica, 128 Academia Rd. 2Sec., Nankang, Taipei, Taiwan \\ ${ }^{2}$ Japan Agency Marine-Earth Science Technology, 3173-25 Showa, Kanazawa, Yokohama, Japan \\ ${ }^{3}$ Faculty of Safety Sciences, Kansai University, 7-1 Shiraume, Takatsuki, Osaka, Japan \\ ${ }^{4}$ Graduate School of Sciences, Hokkaido University, N10-W8, Kita, Sapporo, Japan \\ ${ }^{5}$ Dept. Life Science, National Taiwan University, 4 Roosevelt Rd., Taipei, Taiwan
}

Correspondence to: M. Ando (ando@earth.sinica.edu.tw)

Received: 25 July 2012 - Published in Nat. Hazards Earth Syst. Sci. Discuss.: Revised: 8 May 2013 - Accepted: 23 June 2013 - Published: 6 September 2013

\begin{abstract}
One hundred fifty survivors of the 11 March 2011 Great East Japan Earthquake (Tohoku-oki earthquake) $\left(M_{\mathrm{W}}=9.0\right)$ were interviewed to study the causes of deaths from the associated tsunami in coastal areas of Tohoku. The first official tsunami warning underestimated the height of the tsunami and $40 \%$ of the interviewees did not obtain this warning due to immediate blackouts and a lack of communication after the earthquake. Many chose to remain in dangerous locations based on the underestimated warning and their experiences with previous smaller tsunamis and/or due to misunderstanding the mitigating effects of nearby breakwaters in blocking incoming tsunamis. Some delayed their evacuation to perform family safety checks, and in many situations, the people affected misunderstood the risks involved in tsunamis. In this area, three large tsunamis have struck in the $115 \mathrm{yr}$ preceding the 2011 tsunami. These tsunamis remained in the collective memory of communities, and numerous measures against future tsunami damage, such as breakwaters and tsunami evacuation drills, had been implemented. Despite these preparedness efforts, approximately 18500 deaths and cases of missing persons occurred. The death rate with the age of 65 and above was particularly high, four times higher than that with other age groups. These interviews indicate that deaths resulted from a variety of reasons, but if residents had taken immediate action after the major ground motion stopped, most residents might have been saved. Education about the science behind earthquakes and tsunamis could help save more lives in the future.
\end{abstract}

\section{Introduction}

The 11 March 2011 Great East Japan Earthquake $\left(M_{\mathrm{w}}=9.0\right)$ was the largest earthquake in the region; a possible previous event with an equivalent magnitude is the Jogan earthquake of 869 (Minoura et al., 2001; Sawai et al., 2012). In the $400 \mathrm{yr}$ before this event, eight near-field tsunamis struck the region (Hatori, 1976). Among them and some far-field tsunamis, four were major tsunamis: those resulting from the $1611 M_{\mathrm{t}}=8.4$ Sanriku earthquake $\left(M_{\mathrm{t}}\right.$ is the magnitude defined by tsunami height following Abe, 1999), the $1896 M_{\mathrm{w}}=7.2-M_{\mathrm{t}}=8.2$ Sanriku earthquake, the 1933 $M_{\mathrm{w}}=8.3$ Sanriku earthquake and the $1960 M_{\mathrm{w}}=9.5$ Chile earthquake.

The 1611 earthquake was located near the Japan trench (Hatori, 1976; Sawai et al., 2006). The 1896 tsunami was classified as a tsunami earthquake because its seismic wave radiation was significantly lower than the size of the tsunami generated by the earthquake (Kanamori, 1972). This tsunami resulted in a death toll of 22915 for the Tohoku coast (Usami, 2003; Yamashita, 2005). The 1933 tsunami was an intraslab normal fault near the trench axis (Kanamori, 1971). This tsunami caused a death toll of 3064 for the Tohoku coast (Usami, 2003). The most recent tsunami before the Tohokuoki earthquake was the one that was generated by the 1960 Chilean earthquake and propagated over a distance of 20,000 $\mathrm{km}$ to Japan. This tsunami caused a death toll of 110 for the Tohoku coast (Usami, 2003). Since these tsunamis, numerous breakwaters were constructed along the northeastern 
coasts, tsunami evacuation drills were performed, and hazard maps were distributed to local residents in many communities. However, despite these constructions and preparedness efforts, the 11 March Tohoku earthquake caused numerous fatalities. The Great East Japan Earthquake produced serious tsunamis as well as strong shaking, which caused 18564 deaths, including missing persons (Fire and Disaster Management Agency, FDMA, see the number 1 in Table 1). Hereafter the number in curly brackets \{\} denotes the number of a corresponding URL site in Table 1.

Studies concerning the rupture process of the $M_{\mathrm{w}}=9.0$ Great East Japan Earthquake have been performed intensively based on seismic waves (Lay et al., 2011; Ide et al., 2011; Simons et al., 2011), geodetic data (Sato et al., 2011; Ozawa et al., 2011), tsunami data (Fujii et al., 2011) and integrated datasets (Lee et al., 2011; Koketsu et al., 2011). Figure 1 indicates that the rupture area of the Great East Japan Earthquake covered the offshore Tohoku area with $5 \mathrm{~m}$ and $30 \mathrm{~m}$ fault slip contours on the fault plane (Fig. 1; Lee et al., 2011). The shaking intensity in the devastated area was at least lower-VI on the Japan Meteorological Agency (JMA) intensity scale $\{8\}$, a degree that is VIII or higher on the modified Mercalli scale. The strong shaking lasted at least 2-3 min and was described by local residents as the strongest and longest that they had ever experienced. Inundation and run-up heights of the tsunami reached up to approximately $40 \mathrm{~m}$ and exceeded $10 \mathrm{~m}$ at many devastated areas. The resulting tsunami affected more than 23 cities in which more than 10 persons drowned (Table A in Supplement).

Although $95-97 \%$ of the estimated population who were in the areas severely affected by the tsunami evacuated to safe places, 3-5\% were not so fortunate (Text A in Supplement). To understand why some people evacuated in time while others did not, we interviewed the survivors. Following our previous brief report (Ando et al., 2011), this paper analyses further details of the evacuation behaviours and human thinking behind the evacuation actions by providing additional data. The statistical data such as population, tsunami fatalities and damaged houses were acquired from the Statistics Bureau and the Director General for Policy Planning of Japan (DGPPJ) $\{4\}$; the names, addresses and ages of the deceased were provided by the NPA $\{2\}$. The number of death tolls by small areas in devastated cities are summarized by the Tani laboratory, Saitama University $\{3\}$. The number of deaths including missing persons and three death rates are discussed in the Supplement: (1) for the population for each municipality, (2) for the inundation population provided by the DGPPJ, and (3) for the inundation population estimated from the number of collapsed houses. The death rate of the case 2 for each coastal city is shown in Fig. 1e. The tsunami height data was obtained from the 2011 Tohoku Earthquake Tsunami Joint Survey Group $\{5\}$ whose joint efforts are described by Mori et al. (2011). The data of the tsunami inundation area was provided by the Tsunami Damage Mapping Team, Association of Japanese Geographers $\{6\}$.

\section{Interviewees}

To understand the causes of the high number of deaths, survivors were interviewed at public evacuation shelters with permission or at select houses of the survivors in 6 cities in mid-April and early June 2011 (Fig. 2). Each interview was conducted for approximately $30 \mathrm{~min}$ and focused on the evacuation behaviours of the interviewees and others that they had observed. Some interviewees spoke freely in responding to our questions, with some interviews lasting more than $1 \mathrm{~h}$. However, some interviewees did not provide as much detail. In this survey, we did not emphasize the number of interviews and statistics were not the first priority. Because the number of interviewees is not sufficiently large, our results are not statistically significant to represent the entire devastated area of the 2011 tsunami. The interviewee stories were itemized into 25 questions by the authors; select questions are provided in Table 2. These questions were developed after the interviews, and thus, the responses were selected from the interview transcripts by the authors. Accordingly, all the questions were not necessarily answered by each interviewee.

Three prefectures, Iwate, Miyagi and Fukushima from north to south, suffered the most severe damage from the tsunami (Fig. 1). Iwate predominantly consists of bay and headland areas, and Miyagi and Fukushima predominantly consist of coastal plain areas. $90 \%$ of the interviewees lived in bay and headland areas prior to the 2011 tsunami. We interviewed 125 people in the Iwate prefecture (Yamada, Otsuki, Kamaishi, Ofunato, and Rikuzen-Takada cities) and 25 people in the Miyagi prefecture (Ishinomaki city) (Fig. 2). The tsunami with amplitudes higher than 10-20 m arrived on the shore of our interviewed areas approximately $30-40 \mathrm{~min}$ after the end of the strong shaking of the main shock. The arrival times of the large tsunami waves at tide gauge stations are depicted in Fig. 1. These waves inundated inner-bay towns 3-5 min later.

\subsection{Interviewees}

The interviewees were made up of $55 \%$ male and $45 \%$ female participants, and the age distribution is shown in Fig. 3. This distribution is biased to senior ages compared with the distribution of the population in the devastated areas, where $31 \%$ of the population is $65 \mathrm{yr}$ or older. However, the death ratio of people $65 \mathrm{yr}$ or older was $65 \%$ of the total deaths, four times higher than that for people below $65 \mathrm{yr}$ of age (Fig. 3; see also the age distribution in Table B of Supplement). Because the deaths in the 65 and above age group are very high compared to other groups, our interviews are more suitable to understanding the reasons behind the tragedy. In the Tohoku earthquake, more than $90 \%$ deaths were drownings due to the tsunami (NPA). $83 \%$ of the interviewees were in the inundated areas and the $17 \%$ of them that were in 


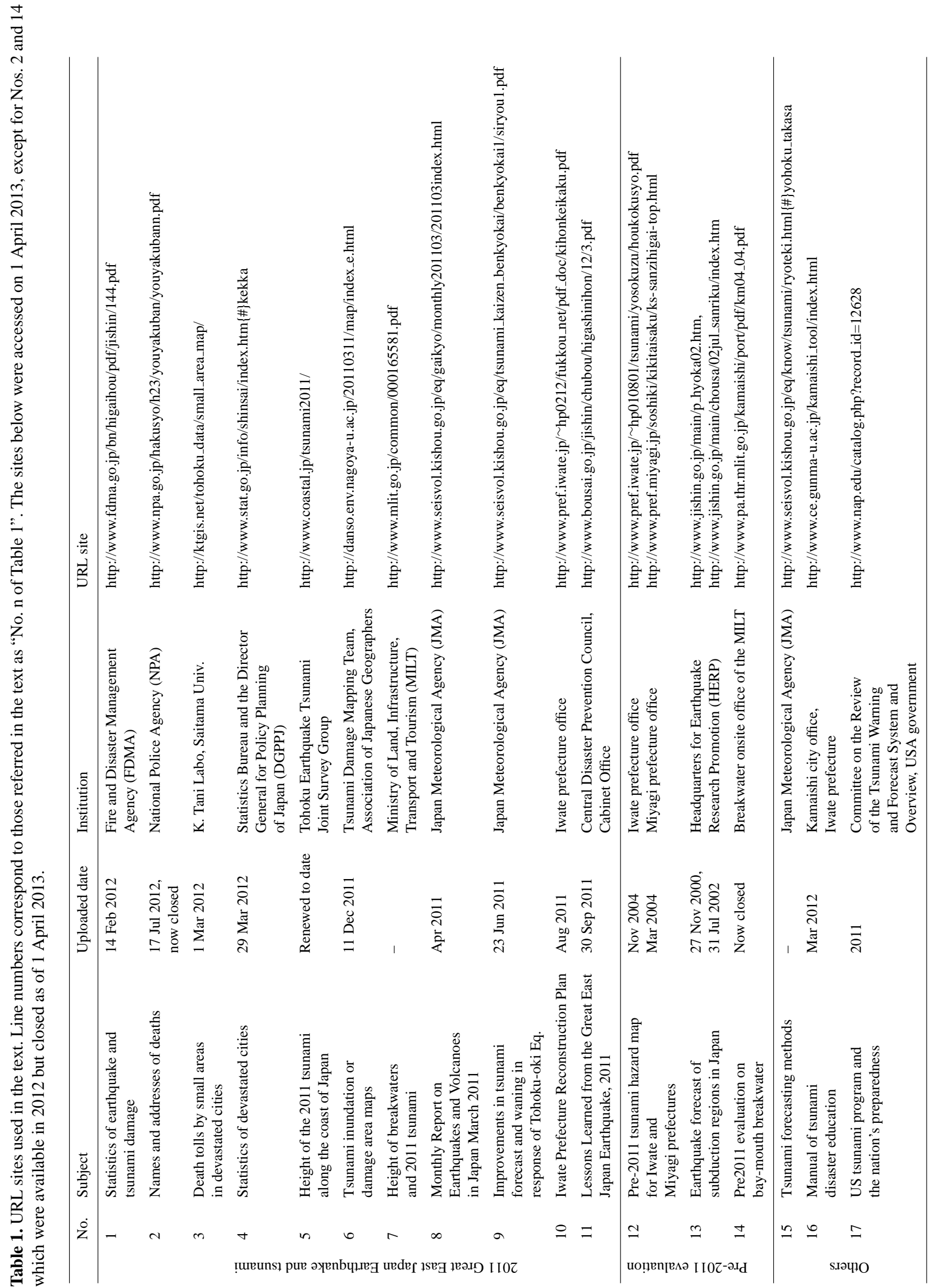




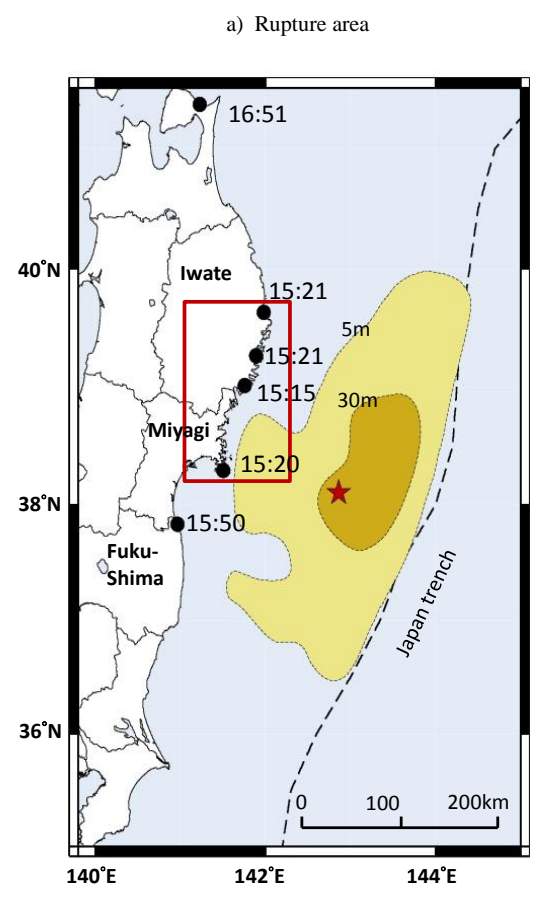

b) Tsunami height c) Tsunami height

d) Death rate e) Breakwater/tsunami

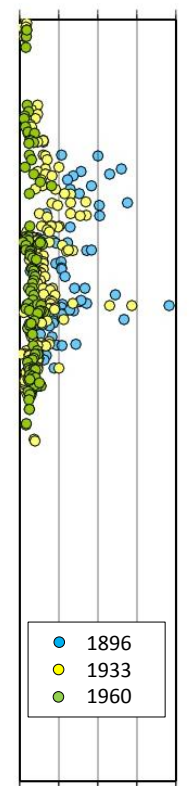

$0 \quad 10203040010203040$

(m)

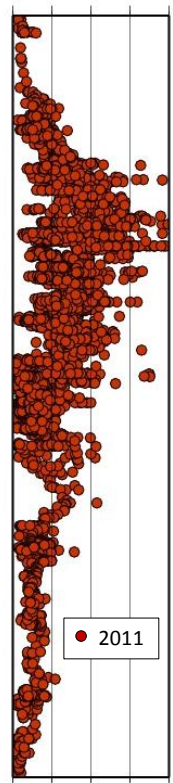

(m)

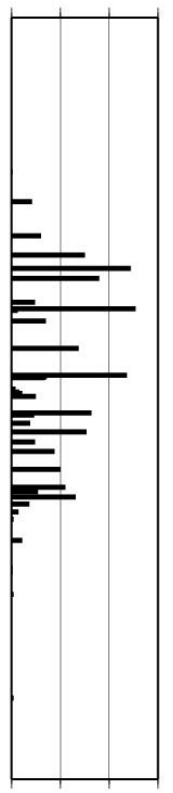

(\%)

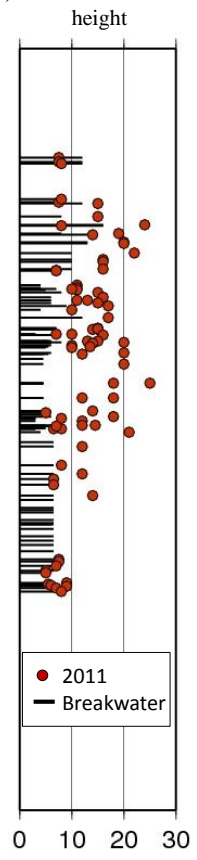

(m)

Fig. 1. (a) The rupture area of the 11 March 2011 Great East Japan Earthquake, including $5 \mathrm{~m}$ and $30 \mathrm{~m}$ fault slip contours (Lee et al., 2011). The epicenter of the main shock (star) and the area in which people were interviewed (red rectangle) are shown. The arrival times of the large tsunami waves at tide gauge stations (black circles) are shown in local time (UT+9 h). These waves arrived at inner-bay towns 3-5 min later. (b) Inundation heights (m) along the Tohoku coast for the 16 June $1896 M_{\mathrm{t}}=8.2$, 3 March $1933 M_{\mathrm{W}}=8.3$, and 23 May $1960 M_{\mathrm{W}}=9.5$ (Chile) tsunamis (Usami, 2003). (c) The wave heights of the tsunami following the 11 March $2011 M_{\mathrm{W}}=9.0$ earthquake (2011 Tohoku Earthquake Tsunami Joint Survey Group, No. 4 in Table 1). (d) The estimated death rate (\%) in the inundated areas of each municipality, following the 2011 Great East Japan Earthquake. The number of deaths and missing persons in each municipality and the inundation areas are provided by the Statistics Bureau and the Director General for Policy Planning of Japan (DGPPJ) (No. 4 in Table 1). (e) The heights of breakwaters and tsunami waves at the corresponding sites (the Central Disaster Prevention Council, Cabinet Office, No. 11 in Table 1). Only in the northernmost areas were the breakwaters higher than the incoming tsunami waves, but the tsunami still flooded through gaps in the breakwaters (Iwate prefecture office).

a deep inland areas or high lands were proved to be safe [see the questionnaire 1 in Table 2]. Hereafter the number in square brackets [ ] denotes the number of a corresponding questionnaire in Table 2.

\subsection{Six interviewed cities}

Figure 2 shows the six cities in which we conducted interviews. The five cities in Iwate prefecture (Fig. 2a-f) were located in typical bay and headland areas. Ishinomaki in Miyagi prefecture was located in a peripheral coastal plain area, but near a bay and headland area (Fig. $2 \mathrm{~g}$ ). The pre2011 forecast tsunami inundation limits from the tsunami hazard maps are shown by red lines (after the Iwate and Miyagi prefecture offices $\{12\}$ ), and the 2011 inundation areas are coloured in blue (after the Tsunami Damage Mapping Team, Association of Japanese Geographers $\{6\}$ ) in which the tsunami heights are shown in meters. Each map shows the percentages of the population (left bar) and the deaths (right bar) for three age groups $(0-15,16-64$, and 65 and above), where the data were collected from Tani (2012). The death tolls and inundation populations are summarized in Table 3. The affected populations were concentrated in the coastal areas. Because the major cities further inland are far from the coastal municipalities, commuting, travelling to school and shopping are generally limited within each city or in the neighbouring coastal cities. The numbers of interviewees are shown in Fig. A in Supplement.

\section{Evacuation behaviours}

In the bay and headland areas, highlands and safer grounds are within $5-20 \mathrm{~min}$ by foot at a normal speed from the tsunami-affected areas. In many locations, sometimes, hills are present just behind dwellings. In contrast, in the coastal plain areas, the tsunami inundated $2-4 \mathrm{~km}$ (Sawai et al., 2012), unlike what was observed in the bay and headland areas. This survey focuses mostly on tsunami evacuation behaviours in the former areas, as mentioned above. 
Table 2. Interviewee responses.

\begin{tabular}{|c|c|c|c|c|}
\hline No. & Question items & No. of interviewees & No. of replies & Replies, \% \\
\hline \multirow[t]{4}{*}{1} & Where were you during the strong shaking? & 150 & 150 & \\
\hline & 1. At an area to be inundated & & 118 & 83 \\
\hline & 2. At a deep inland or high land & & 29 & 15 \\
\hline & 3. N/A & & 3 & 2 \\
\hline \multirow[t]{6}{*}{2} & Did you evacuate safely? & 150 & 150 & \\
\hline & 1. Safely & & 52 & 35 \\
\hline & 2. Slightly dangerous & & 39 & 26 \\
\hline & 3. Very risky, chased by tsunami & & 26 & 17 \\
\hline & 4. Submerged by tsunami & & 8 & 5 \\
\hline & 5. Safe or proved to be safe places & & 25 & 17 \\
\hline \multirow[t]{4}{*}{3} & $\begin{array}{l}\text { Was the shaking strongest and of the longest duration } \\
\text { that you had experienced? }\end{array}$ & 150 & 150 & \\
\hline & 1. Yes & & 145 & 97 \\
\hline & 2. Not so much & & 3 & 2 \\
\hline & 3. N/A & & 2 & 2 \\
\hline \multirow[t]{6}{*}{4} & How did you obtain the tsunami warning information? & 150 & 150 & \\
\hline & 1. None & & 63 & 42 \\
\hline & 2. Bosai Musen (Local outdoor loud speakers) & & 47 & 31 \\
\hline & 3. Media (TV, Radio, etc.) & & 19 & 13 \\
\hline & 4. Someone else & & 13 & 9 \\
\hline & 5. N/A & & 8 & 5 \\
\hline \multirow[t]{9}{*}{5} & What did you do first after the shaking stopped? & 150 & 150 & \\
\hline & 1. Evacuated to a higher place & & 47 & 31 \\
\hline & 2. Verified the safety of family or neighbors & & 41 & 27 \\
\hline & 3. Cleaned things that were scattered & & 22 & 14 \\
\hline & 4. Provided public support for the evacuation of others & & 8 & 5 \\
\hline & 5. Prepared for evacuation & & 10 & 6 \\
\hline & 6. Talked with neighbors & & 6 & 4 \\
\hline & 7. Went to see the incoming tsunami & & 6 & 4 \\
\hline & 8. Other & & 10 & 6 \\
\hline
\end{tabular}

$6 \quad$ For those who did not select 5.1, why didn't you evacuate immediately?

(a maximum of 2 replies for each interviewee)

$103 \quad 138$

1. Expected the incoming tsunami to be small

2. Verified the safety of family or neighbors

3. Believed that current location was high enough

4. The incoming tsunami would not reach my place

5. No consideration of tsunami possibility

6. Other

7 What was the motivation to decide to evacuate?

$150 \quad 150$

1. Own decision based on the strong shaking

2. Someone else's confirmation

3. Seeing the incoming tsunami

4. Safe place, no need to move

5. Bosai Musen (local outdoor announcement)

6. Public media

7. Other

\begin{tabular}{ccc}
103 & 138 & \\
& 47 & 46 \\
40 & 39 \\
& 19 & 18 \\
11 & 11 \\
& 5 & 5 \\
4 & 4 \\
\hline 150 & \\
& 150 & 29 \\
& 44 & 33 \\
49 & 18 \\
27 & 9 \\
13 & 3 \\
10 & 1 \\
5 &
\end{tabular}


Table 2. Continued.

\begin{tabular}{|c|c|c|c|c|}
\hline No. & Question items & No. of interviewees & No. of replies & Replies, \% \\
\hline \multirow[t]{6}{*}{8} & $\begin{array}{l}\text { For those who selected answer } 6.1 \text { above, why did you } \\
\text { believe the incoming tsunami small? ( } 2 \text { replies from } 23 \text { ) }\end{array}$ & 52 & 75 & \\
\hline & 1. Previous repeated tsunami warnings & & 22 & 42 \\
\hline & 2. Experience of the 1960 Chilean tsunami & & 27 & 52 \\
\hline & 3. Nearby breakwaters & & 17 & 33 \\
\hline & 4. Tsunami warning & & 4 & 8 \\
\hline & 5. Other tsunami & & 4 & 8 \\
\hline \multirow[t]{7}{*}{9} & $\begin{array}{l}\text { What was the major transportation mode } \\
\text { used in your evacuation? (150) }\end{array}$ & 150 & 150 & \\
\hline & 1. Foot & & 63 & 42 \\
\hline & 2. Car & & 43 & 29 \\
\hline & 3. Car and walk & & 15 & 10 \\
\hline & 4. Bicycle & & 6 & 4 \\
\hline & 5. Move to upper floor of the same building & & 8 & 5 \\
\hline & 6. Safe place, no need to evacuate & & 14 & 9 \\
\hline \multirow[t]{5}{*}{10} & $\begin{array}{l}\text { Experiences of tsunami } \\
\text { (maximum of } 3 \text { responses for each interviewee) }\end{array}$ & 150 & 252 & \\
\hline & 1. The 1960 Chile tsunami & & 72 & 48 \\
\hline & 2. Heard about past tsunamis & & 69 & 46 \\
\hline & 3. Participation in tsunami drills & & 50 & 33 \\
\hline & 4. The 1933 Sanriku-Oki tsunami & & 4 & 3 \\
\hline \multirow[t]{6}{*}{11} & Did you change your evacuation site one or two times? & 150 & 150 & \\
\hline & 1. Stayed at one site & & 68 & 45 \\
\hline & 2. Moved to a higher site & & 61 & 41 \\
\hline & 3. Others & & 4 & 3 \\
\hline & 4. No need to evacuate & & 13 & 9 \\
\hline & 5. N/A & & 4 & 3 \\
\hline
\end{tabular}

All the data are given as the number of replies and a percentage. Some sections do not have replies from all interviewees. Some sections have two or three replies from an interviewee, where the percentage was calculated with respect to the number of interviewees replying. Hence, the total percentage of such a case exceeds $100 \%$.

\subsection{Safe and unsafe locations}

Among the 150 interviewees, upon feeling the very strong shaking of long duration or receiving tsunami warnings, $35 \%$ promptly evacuated to areas that proved to be safe, $26 \%$ evacuated to areas with only slight problems, $17 \%$ evacuated only after seeing the incoming tsunami approaching behind them, and $5 \%$ were swept by the tsunami but were eventually rescued (Fig. 4a; [2]).

Among the interviewees, $22 \%$ were endangered or submerged and barely escaped. One of the serious cases happened to a female interviewee in her late 60 s who was submerged and swam for $3 \mathrm{~h}$ in cold seawater in the snowy day surrounded by debris before being rescued. She was skillful at swimming from childhood and also lucky to have not been hit by debris. The other $17 \%$ of interviewees were outside the affected area when the tsunami hit; however, many of their houses were destroyed by the tsunami.

\subsection{Tsunami warning}

$97 \%$ of the interviewees described the ground motion as being stronger and of longer duration than they had ever experienced previously [3]. $53 \%$ of the interviewees received the tsunami warning issued by the JMA, either directly or indirectly. Among those who received the JMA's warning, $31 \%$ received it through the wireless administration loudspeakers installed in the communities [4]. Broadcasts were made on battery-operated wireless loudspeakers from the local municipal offices called Bosai Musen (Wireless Disaster Mitigation System), which were installed in most communities. Bosai Musen is used to communicate everyday public information to local communities except for urban areas. For an earthquake and tsunami, warnings and earthquake information are provided through the wireless system by governmental agencies and sent through Bosai Musen by local city offices. Although it was a major communication means for the tsunami warning after the strong 


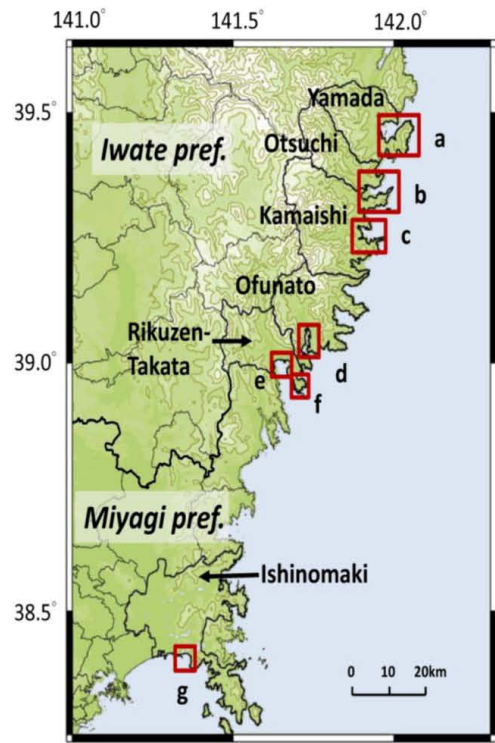

c) Kamaishi

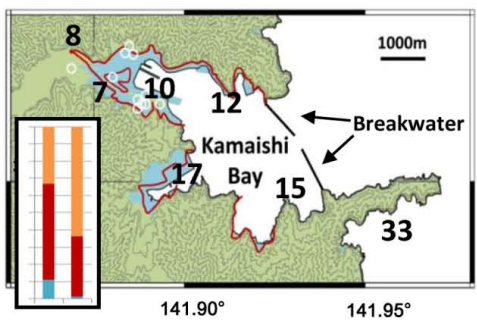

g) Ishinomaki

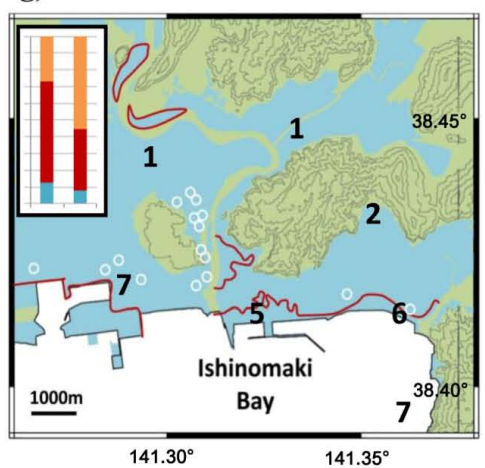

a) Yamada

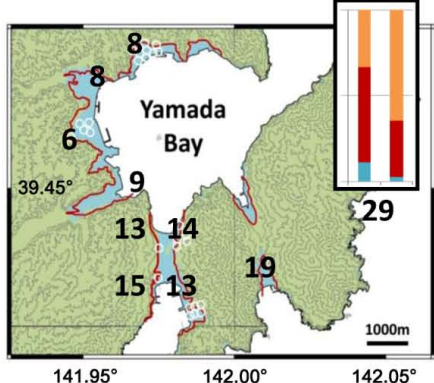

b) Otsuchi

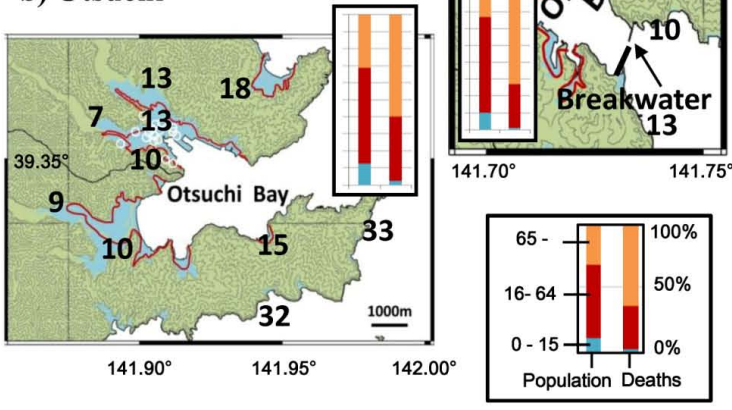

e) Takada, Rikuzen-Takada f) Hirota, Rikuzen-Takada

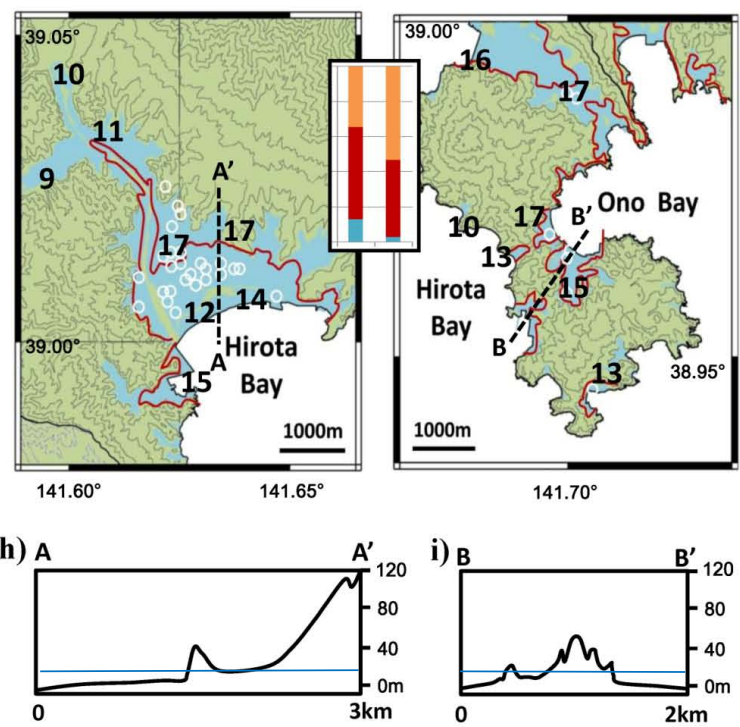

Fig. 2. The six cities in which interviews were conducted. (a)-(g) the map of he interviewed area of each city shown with topographic contour lines at $50 \mathrm{~m}$ intervals. The inundation areas of the 2011 Great East Japan Earthquake (light blue) are provided by the Association of Japanese Geographers (\{6\}, No. 6 in Table 1). The red lines show the tsunami inundation limits that were forecasted in 2006 by the Iwate and Miyagi prefecture offices, based on the scenario earthquakes A, B, and C in Fig. 7 (Iwate and Miyagi prefecture offices \{12\}, No. 12 in Table 1). The forecast inundation limits at each site were taken as the highest values among the three models. Numerals are inundation or runup heights of the observed 2011 tsunami in meter (Tohoku Earthquake Tsunami Joint Survey Group $\{5\}$, No. 5 in Table 1). The major difference is in height; the 2011 tsunami wave heights were 2-5 times higher than the forecasted heights. Each map shows the percentages of the population (left bar) and the deaths (right bar) for three age groups (0-15, 16-64, and 65 and above from bottom to top), where the data were collected from Tani (2012). Subdivision maps Takada and Hirota of Rikuzen-Takada city are depicted separately to compare evacuation behaviours between the two divisions, where the tsunami has wave heights of $12-15 \mathrm{~m}$. Takada is the main subdivision of the city of Rikuzen-Takada, a commercial and business town lying in a wide lowland sand dune. Hirota is also in Rikuzen-Takada and is located in narrow lowlands, where slopes have developed between hills and the seawater is visible almost everywhere. Topographic profiles along Takada (h) and Hirota (i) are shown with a line of $15 \mathrm{~m}$. The number of interviewees who felt the 2011 Great East Japan Earthquake at each location is depicted in Fig. A in Supplement on the same map as Fig. 2. 


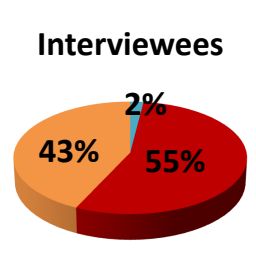

$\mathbf{N}=150$

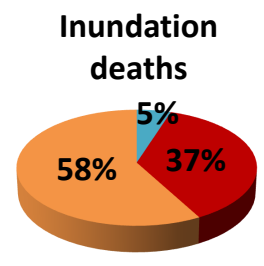

$\mathrm{N}=7,056$

\section{Inundation \\ population}

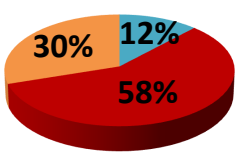

$\mathbf{N}=\mathbf{2 3 9}, \mathbf{0 0 0}$

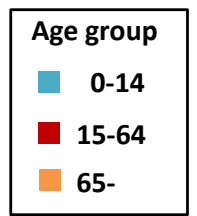

Fig. 3. Demographics of the three age groups: 0-14, 15-64, and 65 and older. The age distribution of the interviewees in this study, the death tolls in the six studied cities and the number of people in the six cities whose addresses were in the 2011 tsunami inundation areas are shown. The data used in the middle and right plots are after Tani (2012). "N" shows the number of samples.

shaking, many issues occurred with properly receiving the tsunami warning. Many people had difficulty in hearing the announcements because of the reverberation of sounds or interference from several nearby speakers. In addition, some were unable to pay attention to the warning. Thus, $42 \%$ evacuated without receiving any tsunami warning information [4].

\subsection{First action}

Although the majority of people expected a tsunami strike, and half of the interviewees received the tsunami warning, $64 \%$ did not take any immediate action to evacuate to higher grounds [5]. They instead returned home to verify the safety of their families (27\%), mostly from work or other places by car. Others cleaned up the items that were in disarray because of the strong shaking (14\%) and/or called and checked on their neighbours or chatted (7\%). Moreover, some of them went to nearby harbours or rivers to see the incoming tsunami (3\%) (Fig. 4b; [6]). They were certainly in dangerous situations but had believed that the tsunami would be small. Many survivors described how they saw some people watching at the breakwaters or harbours, where they were swept away by the tsunami.

\subsection{Motivation for evacuation}

The main motivation that caused the interviewees to evacuate was the unusual shaking (29\%) or the confirmation (or milling) of family or neighbours (33\%) (Fig. 4c; [7]). Although $31 \%$ of the interviewees heard the tsunami warning through Bosai Musen, either directly or indirectly, only $1 / 4$ of the $31 \%$ responded to this warning $[4,7]$. The confirmation (a) What did you do first after the shaking stopped?

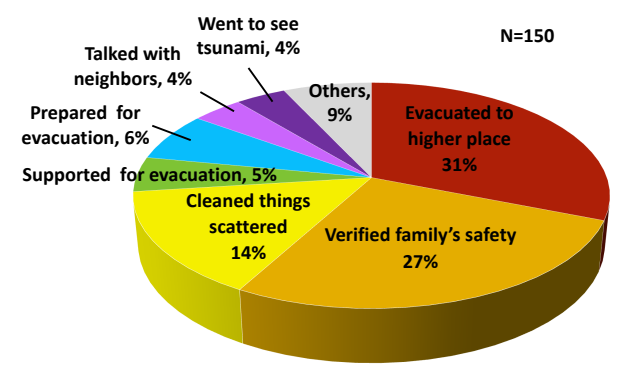

(b) Did you evacuate safely?

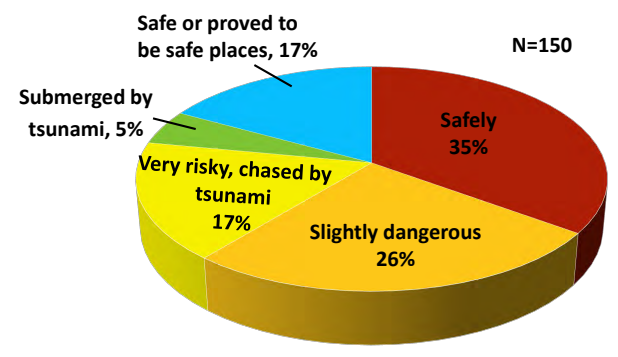

(c) What was the motivation to decide to evacuate?

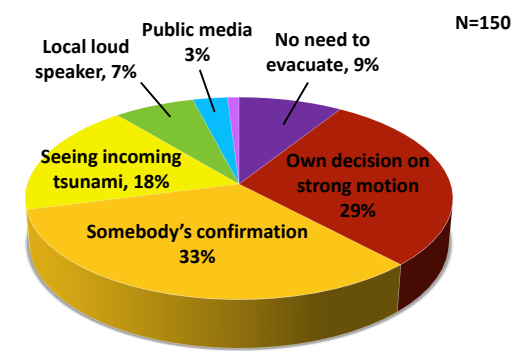

(d) Why didn't you evacuate immediately?

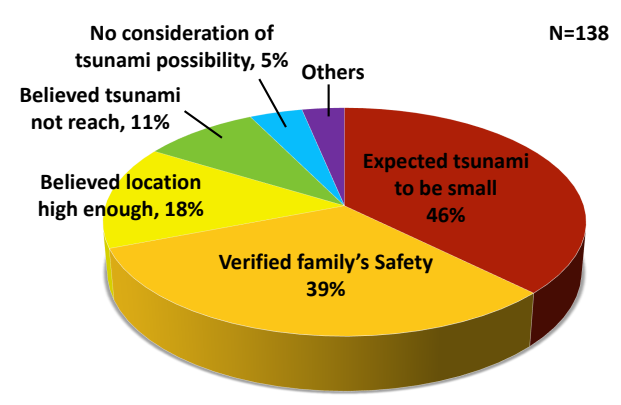

Fig. 4. Replies from the interviewers in response to the questions items. Hereafter the number in block brackets [ ] denotes the number of a corresponding question item in Table 2. (a) [5], (b) [2], (c) [7], and (d) [6]. (d) Two or three replies from an interviewee are included, where the percentage was calculated with respect to the number of 103 interviewees replying. Hence, the total percentage of this case exceeds $100 \%$. "N" in each panel shows the number of samples. 
or milling of others is what led them to evacuate. This is a well-known and effective way of evacuating people in many cases (e.g. JMA $\{8\})$. However, actually seeing the incoming tsunami was the most direct information that prompted interviewees to evacuate (17\%). They saw from afar the smoking muddy floods and/or heard loud crashing sounds as the tsunami destroyed the houses and structures along its path. They also saw the actual tsunami front, which caused many people to flee and run for safety while simultaneously hearing the shouting voices of neighbours or the announcement of Bosai Musen. When one of the evacuees in his 50s turned into one of cross streets from a main street and looked back behind him approximately $10 \mathrm{~m}$ from the corner where he had turned, he had seen "the cross-section" of the tsunami flow containing many cars and miscellaneous debris. Fortunately, the water did not flow into the cross street at that moment and only passed by, and he was able to escape from the tsunami. He is grouped in the category of having escaped under an extremely dangerous situation.

\subsection{Reasons not to immediately evacuate}

The 103 interviewees (65\%) who did not take an immediate evacuation action to higher grounds provided the following reasons ( 32 produced two replies, resulting in a total of 138 replies): $46 \%$ imagined that the incoming tsunami would be small, $39 \%$ needed to return home to verify the safety of their family regardless of the size of tsunami, $18 \%$ believed that the nearby breakwaters were high enough, $11 \%$ believed that they were in a safe place for various reasons, and $5 \%$ never thought about the possibility of a tsunami occurring after the earthquake (Fig. 4d; [6]).

A total of 52 interviewees provided reasons why they had imagined that the incoming tsunami would be small or would have little effect on them. Each interviewee selected 1 or 2 reasons, and a total of 75 reasons were counted. Among them, $52 \%$ interviewees cited direct or indirect experience with the 1960 Chile tsunami, 33\% mentioned the nearby breakwaters, and $42 \%$ mentioned previous JMA tsunami warnings [8]. These reasons will be discussed later.

\subsection{Transportation}

Cars are used in the rural areas on a daily basis much more than in the urban areas in Japan. This factor has produced a car-dependent society, and thus, the use of a car became natural even for tsunami evacuation. Among the interviewees, $39 \%$ evacuated using cars, and among them, $10 \%$ walked or ran after driving; $42 \%$ evacuated by foot either by walking or running; $4 \%$ evacuated using a bicycle; and $5 \%$ remained at home or in an office [9]. In the most devastated areas, people could reach the highlands in several $\mathrm{min}$ to $20 \mathrm{~min}$ on foot at a normal speed. Nevertheless, many chose to use their car to evacuate. Thus, all cars rushed into the streets that led to the highlands, which caused extreme traffic jams. Moreover, this situation became worse when the power shutdown and left everyone in vehicles without traffic lights. In the end, these cars were washed away by the tsunami. It should be noted that in our survey, we did not meet any survivors who escaped or were rescued from a vehicle once it was submerged by the tsunami. This car-dependent tendency of the local population might further increase in the future unless some actions or changes are taken concerning evacuation procedures and instructions.

\section{Discussion}

Based on the above interviews and observations, several issues influenced the local residents' decision "not to evacuate immediately". Most interviewees believed that the incoming tsunami would be small and would not reach their location. The major reasons were that the previous tsunamis were low compared with most communities, and the emergency evacuation sites were not high. Although some reasons were not obvious to the interviewees and not realized by them, several issues were related to earthquake science. Throughout our survey, it was observed that recent earth science or technology did not help in reducing the death rate. Instead, the incorrect earthquake forecast may have increased the death rate to some extent due to the underestimate of the size of the tsunami.

\subsection{Blackout and improper tsunami warning issue}

As mentioned above, approximately half of the people did not receive the tsunami warning. Immediately after the strong ground shaking started, many power plants, substations and supply systems were damaged, and thus, regional electricity was not supplied immediately after the shaking started. People were unable to obtain the tsunami information through $\mathrm{TV}$, which generally provides tsunami warning information to the local residents. In addition, battery-operated radios were not available to most families. Nevertheless, those who were driving their cars were able to listen to the warning from the radio.

The origin time of the earthquake was 14:46 LT (local time $=\mathrm{UT}+9 \mathrm{~h})$. The magnitude calculated by the JMA at 14:49 LT was only 7.9, with estimated tsunami heights of $3 \mathrm{~m}$ in Iwate and Fukushima and $6 \mathrm{~m}$ in Miyagi. Tsunami warnings issued by the JMA are assigned based on seismic waves: they first used $\mathrm{P}$ waves from local seismograms within $3 \mathrm{~min}$ for an immediate warning and then within $15 \mathrm{~min}$ local broad-band seismograms were used to revise the warning. The JMA had tried to shorten the delay in issuing a tsunami warning to three minutes after an earthquake occurred. This goal of the 3 min warning was realized at the 2011 Great East Japan Earthquake. However, the $P$ waves within the first $3 \mathrm{~min}$ of this earthquake were extremely complicated, making it difficult to estimate the size 
Difference between age groups on evacuation situation

(a) Age 12 - 64

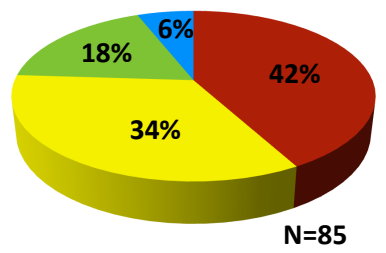

(b) Age above 64

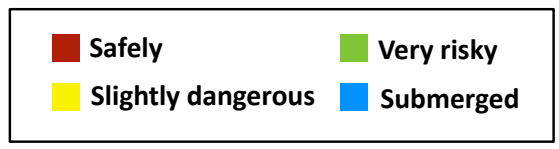

Fig. 5. Replies from the interviewers with the two age groups: 1264 (a) and 65 and above (b) in response to the question item No. 6 in Table 2. "N" in each panel shows the number of samples.

of the earthquake from local strong-motion records (Hoshiba et al., 2011). This tsunami warning was followed by an updated warnings at 15:14 and 15:30 LT \{9\} (Fig. 6). However, these warnings never reached the majority of the local populace. Thus, some residents went to the nearest evacuation sites expecting a relatively small tsunami, while others thought that the tsunami would cause only a small flood and took time to clear fallen debris before evacuating on foot or by car. In fact, the 10 to $20 \mathrm{~m}$ high-tsunami struck most of the interviewed areas between approximately 15:20 and 15:35 LT.

As a result of the first warning, some people turned to information for security. Nevertheless, considering the minimal information that the local inhabitants had received, eventually $95-97 \%$ of the local residents, even in the severely inundated areas, were able to evacuate in time (Supplement). We questioned some of the interviewees about how they would have reacted if a warning of a 10-15 m high tsunami had been initially issued. Among the interviewees, 30 responded that they would have evacuated immediately. Although it is an ex post facto question, these answers imply that a more timely warning giving a more accurate estimate of the tsunami height may have effectively saved human lives.

Regarding the tsunami early warning system, the data from real-time pressure gauges installed 46 and $76 \mathrm{~km}$ off the coast (Fig. 6) were unfortunately not used in real time, although the data were transmitted continuously in real time to the JMA and the University of Tokyo. As shown in Fig. 6, the TM1 water pressure gauge, located in the area of major coseismic crustal deformation, had detected a tsunami with a height of $2 \mathrm{~m}$ at 14:55 LT and of 5.2 $\mathrm{m}$ at 15:00 LT. These parts of the wave arrived at the coast approximately 25 and 20 min later, respectively, and its height was amplified 6 times $(12 \mathrm{~m}$ and

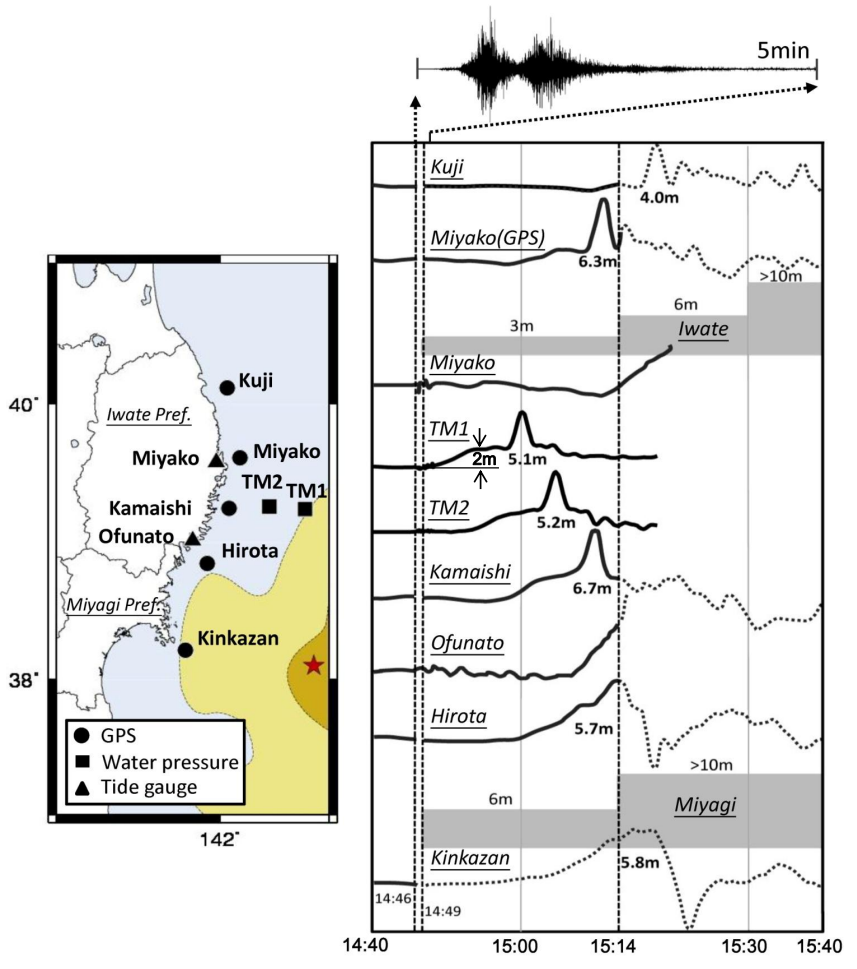

Fig. 6. Tsunami waveforms recorded at ocean-bottom pressure gauges (TM1 and TM2), five GPS buoy wave meters and two tidal gauge stations. The solid lines show the time ranges during which the data were monitored in real time, and the dashed lines show those for which data were stored at onshore stations and recovered later due to the blackout. At the top, the vertical strong-motion record from station HTKD of the National Institute of Disaster Mitigation and Science (NIED) is shown. HTKD was located near the tide gauge station Ofunato (solid triangle). $5 \mathrm{~min}$ after the origin time of the 2011 Great East Japan Earthquake. The gray boxes show the forecasted tsunami heights for Iwate (upper) and Miyako (lower) prefectures, issued by the first warning at 14:49 LT, the second at 15:14 LT, and the third at 15:30 LT. The major tsunami waves struck the interviewed towns at approximately 15:20-15:30 LT. The $5 \mathrm{~m}$ and $30 \mathrm{~m}$ fault slip contours for the Great East Japan Earthquake are also shown (Lee et al., 2011). The epicenter of the main shock is indicated by the star.

$30 \mathrm{~m}$, respectively) at the coastal areas, according to an estimate of tsunami height based on Green's law (JMA $\{15\}$, accessed on 13 April 2013). The wave was recorded at TM2 5 min after it was recorded at TM1. 10 min later, the offshore Kamaishi GPS wave meter recorded the same tsunami wave. If the data recorded at the pressure gauges had been used in real time for tsunami warning, more lives would have been saved, although many communication systems had already been damaged by that time. Eventually, this record was utilized at 15:30 LT for the third tsunami warning from the JMA (Fig. 4), which was too late to be delivered to most people. At the time of the earthquake, the JMA used the pressure gauges 
as a secondary data source for tsunami warnings. The use of water pressure gauges for tsunami warnings was authorized on 9 March 2012, a year after the earthquake, at which point the JMA explained that technical concerns with the pressure gauges had been largely solved.

The Geographical Survey Institute (GSI) received data in real time from onshore GPS sites at the time of the Great East Japan Earthquake, but it had not started using real-time kinematic GPS (RTK-GPS) for tsunami warnings. If it had been used for tsunami warnings, it would have revealed that the earthquake was much larger than $M=7.9$. The GSI started using RTK-GPS, following Ohta et al. (2012). However, the JMA has not yet used this for tsunami warning. Because only the JMA is allowed to issue a tsunami warning by law, the RTK-GPS is not yet used for tsunami warning.

\subsection{Previous tsunami experience [10]}

Residents over 85 yr of age (10\% of the population) had experience with the 1933 tsunami. Although they did not lead the evacuation efforts, they were able to transfer their knowledge to their descendants. In addition, residents over $55 \mathrm{yr}$ of age (50\% in population) experienced and remembered the 1960 Chile tsunami [10] and transferred their knowledge to the younger generations. As mentioned in a previous section, some of experience led to assumptions concerning the incoming tsunami height or its inundation area in their communities based on the heights of the 1960 tsunami. Some clearly remembered that in 1960, the sea level slowly raised as if filling the water in a swimming pool. This sense of "knowing" that "the tsunami will be small" based on their previous experience put their lives at a very high risk. They did not anticipate at all that the tsunami would approach and rise rapidly and violently.

Similarly, the residents had used to the JMA's previous tsunami warning. JMA had issued 15 warnings or alerts of a tsunami in the preceding $4 \mathrm{yr}$ in Japan. In many cases, the tsunamis that affected the coasts were relatively small or negligible. These frequent warnings, coupled with an overestimated tsunami height, produced a false sense of security to the residents. Unfortunately, in contrast, the 11 March warnings issued at 14:49 and 15:14 LT by JMA was underestimated in terms of both the magnitude and tsunami heights, which resulted in inaction, improper decisions and/or delayed evacuation. Many interviewees underrated the tsunami warning as usual and did not take it seriously for immediate evacuation [8].

\subsection{Incorrect earthquake forecast}

Earthquake forecasting is based on the study of earthquakes. The Headquarters for Earthquake Research Promotion (HERP), a governmental office, issued an earthquake forecast with earthquake magnitudes and probabilities for the entire plate boundaries and active faults in Japan $\{13\}$. The forecast events for the Tohoku region were also provided but proved to be much smaller than that of the actual magnitude of the 2011 Tohoku earthquake (Fig. 7). The reason behind this is that the committee divided the seismogenic zone off the Tohoku region along the Japan trench into 10 segments based on the last $400 \mathrm{yr}$ earthquake history. The HERP also assumed that these segments would generate earthquakes almost independently. Based on these assumptions, the earthquake magnitude calculations could provide estimates of the corresponding hazards. As a result, the maximum magnitude estimate for the segment of the offshore Miyagi prefecture (Segment "x" in Fig. 7) was 7.5, with a $99 \%$ probability of occurrence in the next $30 \mathrm{yr}$. This probability of "99\%" was well known through the media, and many interviewees were aware of the "offshore Miyagi prefecture earthquake".

Iwate and Miyagi prefecture offices developed tsunami hazard maps based on the forecast by the HERP. There were three scenario earthquakes, of which faults are shown by rectangles of A-C (Fig. 6): (A) an earthquake similar to the 1896 earthquake, (B) an earthquake similar to the 1933 earthquake, and (C) the $M_{\mathrm{w}}=8.0$ hypothetical compound offshore Miyagi prefecture earthquake (three rectangles in segments " $x$ " and " $y$ "). The tsunami inundation limit was considered to be the highest estimate at each site for the three scenario earthquakes. In Iwate prefecture, the highest tsunami estimates were mostly from the 1896 tsunami, while in Miyagi prefecture, the highest tsunami estimates were from the compound offshore Miyagi prefecture earthquake. However, due to the small anticipated magnitudes of these earthquakes, the expected tsunami heights were much lower than the actual heights for the 2011 tsunami. The red lines in Fig. 2 show tsunami inundation limits obtained from these assumptions. In the bay and headland areas, the estimated tsunami limits were similar to those of the 2011 tsunami (Fig. 2a-f), while the height of the estimated incoming waves were $1 / 3$ to $1 / 10$ of those of the 2011 tsunami. The estimation of fatalities from the scenario earthquakes (the Iwate prefecture office $\{7\}$ ) are much smaller by $1 / 6$ to $1 / 10$ than that associated with the 2011 Great East Japan Earthquake.

Many evacuation shelters were constructed even in the pre-2011 tsunami hazard areas in Fig. 2. $48 \%$ of the interviewees initially evacuated to these designated evacuation sites [11]. However, the Tohoku earthquake was much larger than expected, affected a broader area, and produced a much higher tsunami than the anticipated earthquakes, and many evacuees moved from their initial evacuation sites after seeing the height of the incoming tsunami. However, some people were not as lucky and were swept away while still in the evacuation shelters. The evacuation centers were determined based on the study of the scenario earthquakes, which involved risk assessments and either indirectly or directly affected the preparedness of the residents. In short, the inaccurate forecast resulted in increased casualties in the local populations. A councilman in a small town regretted that the 


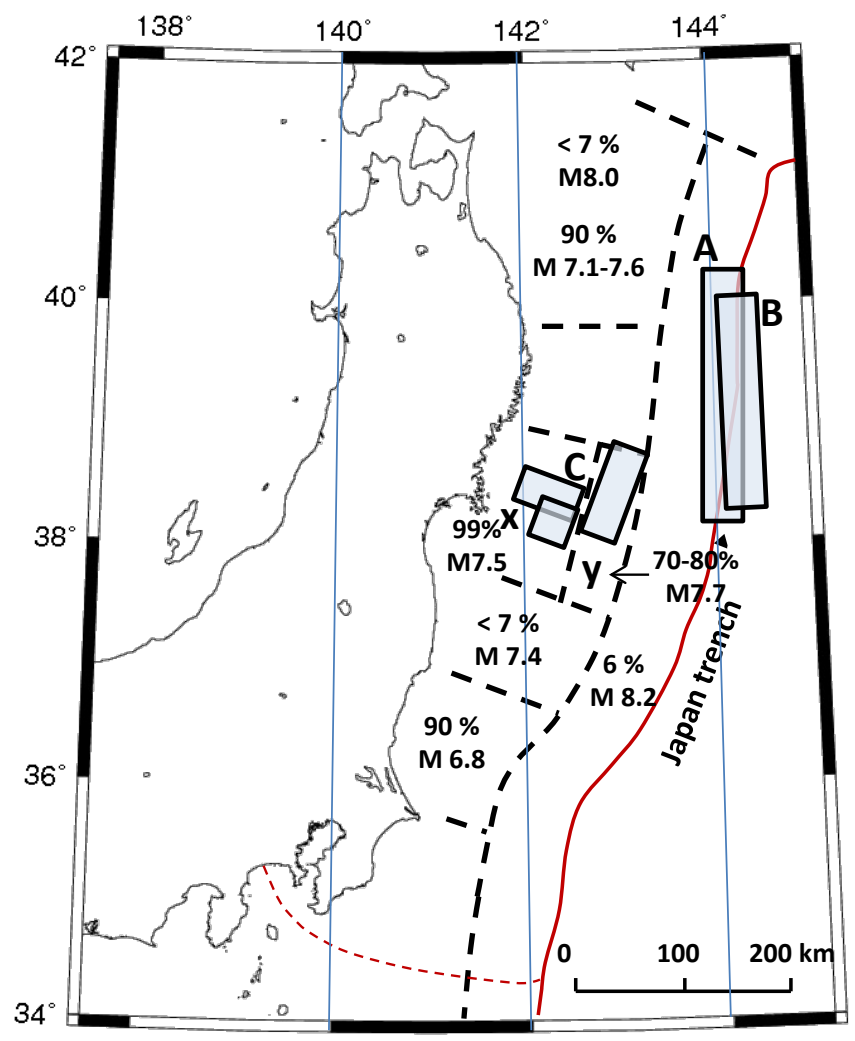

Fig. 7. Forecasted fault segments on the plate interface near the Tohoku region between $35^{\circ}$ and $41^{\circ} \mathrm{N}$ (Headquarters for Earthquake Research Promotion - HERP, 2002; \{13\} No. 13 in Table 1). Among the eight segments, five ruptured during the 2011 Great East Japan Earthquake. The $30 \mathrm{yr}$ probability and the magnitude estimated by HERP are given on the map. The rectangles A, B and C show the fault planes for the three scenario earthquakes, similar to the 1896 Sanriku earthquake, the 1933 Sanriku earthquake, and the Compound Offshore Miyagi prefecture earthquake, respectively, near Iwate and Miyagi prefectures.

community shelters had been built at such low sites based on the hazard map.

However, it is worth noting that the forecast of the offshore Miyagi prefecture earthquake encouraged the local residents to reinforce their houses in advance against strong ground motions. Statistics are not available on how many houses were reinforced for the earthquake countermeasure; however, the percentage of damaged buildings is low in the Tohoku area where the seismic intensity reached VI+ on the JMA scale (VIII or higher on the MM scale) $\{6\}$.

\subsection{Nearby breakwaters}

Local residents thought that breakwaters and seawalls would prevent a tsunami from coming onshore in the coastal area of Tohoku before the 2011 Great East Japan Earthquake. However, the tsunami heights in 2011 exceeded almost all breakwaters, as shown in Fig. 1e. $60 \%$ of breakwaters in Iwate pre- fecture were damaged or destroyed by the tsunami (the Iwate prefecture office $\{10\}$ ). In bay and headland areas of Iwate prefecture, the inundation areas estimated prior to the 2011 tsunami are similar to those observed for the 2011 tsunami near the bases of hills and mountains. Despite the tsunami hazard maps, some people assumed that nearby breakwaters could protect their areas from the tsunami or, at worst, that the tsunami would only cause small floods. Others decided to stay at home and move to the second floor for protection from a high tsunami wave. This is partly due to the low estimated tsunami heights published as a part of hazard maps before 2011 (Fig. 1e). The estimated fatalities for the six cities for scenario earthquakes are very small compared to a result of the 2011 tsunami $(1 / 10-1 / 20)$. These estimates involve several scenarios that include the effects of the vulnerability of breakwaters due to strong shaking, the season and the time it takes for residents to evacuate. We adopted a case similar to the situation in 2011. In reality, local residents were not very familiar with the tsunami hazard maps, but they were aware of the locations of evacuation centers.

Another example is Kamaishi, where a large breakwater was constructed at a depth of $60 \mathrm{~m}$ in the mouth of Kamaishi bay (Fig. 2c). The breakwater office of the Ministry of Land, Infrastructure, Transport and Tourism (MILT) indicated that the breakwater would reduce the tsunami height to $0.6 \mathrm{~m}$, even for the tsunami of the 1896 earthquake $\{14\}$. The president of an ironworks company felt the unusual shaking and heard the announcement regarding the expected $3 \mathrm{~m}$ tsunami height. Based on this information, he allowed his employees to return home immediately because he thought that the breakwater near the mouth of the bay would prevent the tsunami from coming onshore. However, the tsunami reached a height of $10 \mathrm{~m}$ in the area. The president of the factory said that if the tsunami warning had been more accurate and if the efficacy of the breakwater had been correctly assessed and publicized, he would never have sent his employees home. Instead, they could have evacuated together to the nearby highlands immediately behind the factory.

\subsection{Distance from the shore}

We found a remarkable difference in the evacuation behaviours of the interviewees depending on the distance from the coast, even within the same city. In general, residents near the sea or shore were well prepared against tsunamis and liable to rapidly evacuate after the earthquake compared with those who lived inland a small distance from the sea (400$500 \mathrm{~m})$.

To understand more about the evacuation behaviours of the tsunami survivors, we focused our interview in RikuzenTakada city. The city is located in the southernmost part of the Iwate prefecture, which is divided into 8 administrative subdivisions. Among them, we focused on the Takada (Fig. 2e) and Hirota (Fig. 2f) subdivisions, where the tsunami affected almost over the entire districts with a height of 
Table 3. Information about the six cities where the interviews were performed in this study.

\begin{tabular}{lcccccc}
\hline City & Yamada & Otsuchi & Kamaishi & Ofunato & Rikuzen-Takada & Ishinomaki \\
\hline 1. Population of city & 18625 & 15277 & 39578 & 40738 & 23302 & 160704 \\
2. No. of deaths & 604 & 822 & 888 & 339 & 1555 & 3182 \\
3. No. of missing persons & 156 & 484 & 159 & 86 & 291 & 557 \\
4. No. of completely collapsed houses & 2762 & 3092 & 2955 & 3829 & 3159 & 22357 \\
5. Average number of household members & 2.8 & 2.7 & 2.5 & 2.7 & 2.7 & 2.8 \\
6. Estimated population of high inundation area & 7788 & 8325 & 7266 & 10530 & 8609 & 62147 \\
7. Inundation death rate, $\%$ & 10.6 & 15.7 & 14.4 & 4.0 & 21.4 & 6.0 \\
8. No. of interviewees & 30 & 15 & 37 & 8 & 38 & 22 \\
9. Interview sites & IHs & PECs & PEC + IHs & PECs & PECs & PECs + IHs \\
\hline
\end{tabular}

Data for items 1-3 were acquired from the Fire and Disaster Mitigation Agency (FDMA, $\{1\}$, No. 1 in Table 1, as of 14 February 2012 , as of 14 February 2012), for items 4 and 5 from the Statistics Bureau and the Director General for Policy Planning of Japan (DGPRJ, \{4\}, No. 4 in Table 1). Item 6: the product of items 4 and 5; item 7: the division of item 6 by item 1; item 9: interview site, IH = individual house, PES = public evacuation center.

Table 4. Population and fatality information for subdivisions in Rikuzen-Takada city.

\begin{tabular}{lcc}
\hline Subdivision & Takada & Hirota \\
\hline 1. Population & 7641 & 3407 \\
2. No. of deaths & 1052 & 54 \\
3. No. of deaths + missing persons & 1249 & 64 \\
4. High inundation death rate, \% & 16.3 & 1.9 \\
\hline
\end{tabular}

See Fig. 2 for the locations of the subdivisions of Rikuzen-Takada city. Item 1 provided by Statistics Bureau and the Director General for Policy Planning of Japan (DGPPJ, $\{4\}) ; 2$ by National Police Agency (NPA, $\{2\}$ ); 3 : the number of missing persons by subdivision is not available and is assumed to be proportional to the number of the death toll.; 4: see Table A in Supplement. The numbers of deaths were acquired from the National Police Agency. Note that the percentage for Takada is 8 times higher than that for Hirota.

$12-15 \mathrm{~m}$. Takada is mainly a commercial town developed on a wide low-lying area, surrounded by headlands and narrow bays (Fig. 2h). However, Hirota is located in narrow lowlands developed between hills and the ocean (Fig. 2i). We interviewed 42 survivors in the city. The statistical details regarding the population in these two subdivisions are similar to those in the other devastated towns.

Because statistics concerning the collapsed houses and inundation by subdivision are not available, we took the mean inundation deaths divided by the population in each subdivision. The addresses of deaths by subdivision are provided by the NPA. In Takada, the death rate of the devastated area reached $18.8 \%$ (Table 4 ). Because $80 \%$ of the houses in Takada were swept away by the tsunami, the high inundation death rate may be higher but not by much.

The death rate is partly attributed to evacuation shelters that were located on lowlands. Major facilities such as the city office, the municipal stadium, the city hall, and even the city high school that were all designated as tsunami evacuation centers were located in low-lying areas. During the 11 March tsunami, many citizens ran and took refuge in those facilities. However, 32 shelters were destroyed by the tsunami. For example, 70 persons fled into the City Center, and only 11 of them survived. After the major ground shaking, a woman in her 60 s dashed into the city center located $50 \mathrm{~m}$ from her home. When she reached the third floor, the tsunami struck the building, breaking the windows, and water entered the entire building. She was submerged and pushed against the ceiling by the seawater. Fortunately, there was a small gap between the ceiling and the water, and she was able to breath and survived. During that day, wet and cold in the snowy environment, she waited until the following morning. She was rescued by a police helicopter over the rubble and other dead bodies that had piled up.

Despite the proximity of the town of Takada to the sea, several interviewees said that they had not realized how close it was to the ocean and how low the land was in this area. One of the major reasons was that the town was surrounded by breakwaters, houses, shopping centers and the railway, and the local residents blocked the view of the sea. Local inhabitants believe that they are deeper inland than in reality. After the tsunami had swept the buildings and houses away, local residents were even surprised to see that their town is actually located in a very flat lowland.

In contrast, Hirota Town is surrounded by the sea (Fig. 2f), which is visible in every location in the town. The fatality rate in this town was $1.9 \%$ (Table 4), and among the 20 interviewees, $80 \%$ ran up to the hill immediately after the strong shaking. Some of them who did not evacuate immediately saw the incoming tsunami and were able to run afterwards and were saved. In comparison to the people in Takada, the Hirota population has always been more concerned about tsunamis.

\subsection{The elderly and the physically disabled}

As is shown in Figs. 2 and 3 and Table B, $62-72 \%$ of the deaths occurred among the elderly (age 65 and above), which corresponds to a death rate that is four to six times higher than other age groups. One noticeable difference is found in the responses to the question [2] "Did you evacuate safely?". 1.3 times as many in the age 65 and above group responded 
with "Very risky, chased by tsunami" as those in younger groups (Fig. 5). The difference between the two groups was not very large, but it may have been critical to the senior group. A man in his 30s described how he ran up along a hill with his parents, chased by the tsunami. His parents had initially followed him, but after a short time, he looked back and observed that his mother had disappeared. His family did not evacuate immediately; they had spent some time at home before evacuating. There are a number of reasons that people delayed their evacuation, and such delays may have seriously endangered in particular the elderly who needed a longer time than the younger generations to evacuate to high lands. This might cause the significantly high death rate with the age 65 and above.

$16 \%$ of those in the age 65 and above group require long-term care in Iwate and Miyagi prefectures, according to statistics from 2011 provided by the Ministry of Health, Labor and Welfare. In the area, $33 \%$ of the population is age 65 and above. Therefore, at least $5 \%$ of the population requires care or has mobility problems. We found that when an elderly member of a family is bedridden, a spouse or child often remained at home, even during the earthquake. This may have increased the death rate and cannot be solved by a better warning system or by tsunami drills. Among the inundation population in Iwate and Miyagi prefectures (635 000), the deaths of those age 65 and above is 7693 resulting in the death rate of $1.2 \%$ according to Tani (2012). This implies that at least $76 \%$ of population with mobility problems in the age 65 and above group were rescued, which should be considered when further analysing how to reduce deaths of the elderly.

\subsection{Knowledge of tsunami}

Although $17 \%$ of the interviewees evacuated under dangerous conditions and $5 \%$ were swept by the tsunami, it was fortunate that $95-97 \%$ of the total population survived the tsunami in the extremely high tsunami inundation (Table A in Supplement). Comparing the fatality rate (11-27\% in Aceh) associated with the 2004 Sumatra tsunami (Dooce et al., 2007), it is very low. This result was possible because most people knew that tsunamis can occur after earthquakes in Tohoku. Furthermore, throughout our survey, we observed that most interviewees knew their assigned emergency evacuation sites. The knowledge of the local residents concerning tsunamis made the death rate significantly low, even in the extremely high tsunami inundation areas. Most of the residents had participated in tsunami drills at schools, and some joined annual drills on memorial days held in their communities. However, many interviewees did not join drills because of their business or a decrease in interest in tsunamis with time. The interviewees above $55 \mathrm{yr}$ of age remembered the tsunami following the $M_{\mathrm{w}}=9.51960$ Chile earthquake. Over time, they said they became insensitive to tsunamis and did not maintain their interest in tsunami measures for a long time.

We recognized throughout the survey that most people did not understand how a tsunami is created under the sea. Therefore, the relation between earthquakes and tsunamis is not clearly linked. An important issue during tsunamis to save lives is to "evacuate to higher and safe places immediately after a big earthquake". It is a sufficient rule and is the most basic tool for local residents to survive tsunamis. However, it is difficult to sustain such a simple rule for tens or hundreds of years from generation to generation. It is necessary for the population to learn a simple mechanism of the generation of a tsunami in elementary school, especially as children have fresh minds. Although it requires time, this education is essential to ensure proper action during a tsunami in any location. Tsunami disaster education has been conducted at numerous places by many groups and institutions (e.g. Kamaishi city $\{16\}$; the Committee on the Review of the Tsunami Warning and Forecast System and Overview, USA government $\{17\}$ )

\section{Conclusions}

These interviews indicated that many deaths resulted because current technology did not properly function, earthquake science underestimated the earthquake size and tsunami heights, warning systems failed, and breakwaters produced a false sense of security. The advanced technology did not work properly, especially at the time of the severe disaster. If residents had taken an immediate action after the major shaking stopped, most local residents might have been saved because highlands and safer grounds are within 5-20 min on foot from the interviewed tsunami-affected areas, although the elderly and physically handicapped people would still be in a much more difficult situation. Nevertheless, even if these problems occur in future earthquakes, better knowledge regarding earthquakes and tsunami hazards could save more lives. People must take immediate action and identify locations that are higher than the designated evacuation sites, while encouraging others to evacuate and not spend time searching for others, regardless of any official tsunami warning. Such basic and simple knowledge can lead local residents to evacuate sooner, enabling more people to survive a tsunami even if warning systems or other technology cannot function at all. To avoid similar high tsunami death ratios in the future, residents, including young children, should be taught the basic mechanism of tsunami generation.

\section{Supplementary material related to this article is available online at: http://www.nat-hazards-earth-syst-sci.net/13/2173/2013/ nhess-13-2173-2013-supplement.pdf.}


Acknowledgements. Many survivors agreed to be interviewed despite facing hardships at the evacuation shelters. We thank B. Atwater and R. Stein for their constructive comments and suggestions for improving the manuscript. We thank S. Yoshioka, C.-H. Lin and G. O. Besana for their helpful discussions and encouragement. We thank N. Matta, N. Sugito, Y. Ohta, Y. Tanaka, and M. Takahashi for providing data. We are also grateful for the assistance provided by S. Kitamura, Y. Aono and Y. Tahiro. Tsunami inundation area maps were drawn using the data provided by the Tsunami Damage Mapping Team, Association of Japanese Geographers. Figures were plotted using the GMT software. This study was initiated a Tohoku-oki earthquake research project organized by the Research Center for Urban and Safety and Security (RCUSS) at Kobe University. The RCUSS supported part of our travel expenses. This study was supported by a grant (NSC 101-2116-M-001-037) from the National Science Council of Taiwan.

Edited by: T. Glade

Reviewed by: R. Stein and B. F. Atwater

\section{References}

Abe, K.: Quantification of historical tsunamis by the Mt Scale, Zisin (Journal of the Seismological Society of Japan), 2nd Series, 52, 369-377, 1999 (in Japanese with English abstract and figure captions).

Ando, M., Ishida, M., Hayashi, Y., and Mizuki, C.: Interviews with survivors of Tohoku Earthquake provide insights into fatality rate, EOS T. Am. Geophys. Un., 92, 411-412, 2011.

Doocy, S., Gorokhovich, Y., Burnham, G., Balk, D., and Courtland, R.: Tsunami Mortality Estimates and Vulnerability Mapping in Aceh, Indonesia, Am J. Public Health, 97 (Suppl. 1), S146-S151, doi:10.2105/AJPH.2006.095240, 2007.

Fujii,Y., Satake, K., Sakai, S., Shinohara, M., and Kanazawa, T.: Tsunami source of the 2011 off the Pacific coast of Tohoku Earthquake, Earth Planets Space, 63, 815-820, 2011.

Hatori, T.: Propagation of tsunamis from sources off the Pacific coast of northeast Japan, Bulletin of the Earthquake Research Institute, Tokyo University, Tokyo, 51, 197-207, 1976 (in Japanese with English abstract and figure captions).

Hoshiba, M., Iwakiri, K., Hayashimoto, N., Shimoyama, T., Hirano, K., Yamada, Y., Ishigaki, Y., and Kikuta, H.: Outline of the 2011 off the Pacific coast of Tohoku earthquake $\left(M_{\mathrm{W}} 9.0\right)$ - Earthquake early warning and observed seismic intensity, Earth Planet Space, 63, 547-551, doi:10.5047/eps.2011.05.031, 2011.

Ide, S., Baltay, A., and Beroza, G. C.: Shallow dynamic overshoot and energetic deep rupture in the $2011 M_{\mathrm{w}} 9.0$ Tohoku-Oki earthquake, Science, 332, 1426-1429, doi:10.1126/science.1207020, 2011.

Kanamori, H.: Seismological evidence for a lithosperic normal faulting - The Sanriku earthquake of 1933, Phys. Earth Planet. In., 4, 289-300, 1971.

Kanamori, H.: Mechanism of tsunami earthquakes, Phys. Earth Planet. In., 6, 346-359, 1972.

Koketsu, K., Yokota, Y., Nishimura, N., Yagi, Y., Miyazaki, S., Satake, K., Fujii, Y., Miyake, H., Sakai, S., Yamanaka, Y., and Okada, T.: A unified source model for the 2011 Tohokuearthquake, Earth Planet. Sc. Lett., 310, 480-487, 2011.
Lay, T., Ammon, C. J., Kanamori, H., Lian Xue, and Kim, M. J.: Possible large near-trench slip during the $2011 M_{\mathrm{w}} 9.0$ off the Pacific coast of Tohoku Earthquake, Earth Planets Space, 63, 687692, 2011.

Lee, S.-J., Huang, B.-S., Ando, M., Chiu, H.-C., and Wang, J.H.: Evidence of large scale repeating slip during the 2011 Tohoku-Oki earthquake, Geophys. Res. Lett., 38, L19306, doi:10.1029/ 2011GL049580, 2011.

Minoura, K., Mamura, F., Sugawara, D., and Kono, Y.: The 869 Jogan tsunami deposit and recurrence interval of large-scale tsunami on the Pacific coast of northeast Japan, J. Natural Disaster Science, 23, 83-88, 2001.

Mori, N., Takahashi, T., Yasuda, T., and Yanagisawa, H.: Survey of 2011 Tohoku earthquake tsunami inundation and run-up, Geophys. Res. Lett., 38, L00G14, doi:10.1029/2011GL049210, 2011.

Ohta, Y., Kobayashi, T., Tsushima, H., Miura, S., Hino, R., Takasu, T., Fujimoto, H., Iinuma, T., Tachibana, K., Demachi, T., Sato, T., and Ohzono, M.: Quasi real-time fault model estimation for near-field tsunami forecasting based on RTK-GPS analysis: Application to the 2011 Tohoku-Oki earthquake $\left(M_{\mathrm{W}} 9.0\right)$, J. Geophys. Res., 117, B02311, doi:10.1029/2011JB008750, 2012.

Ozawa, S., Nishimura, T., Suito, H., Kobayashi, T., Tobita, M., and Imakiire, T.: Coseismic and postseismic slip of the 2011 maginutde-9 Tohoku-Oki earthquake, Nature, 475, 373-376, doi:10.1038/nature10227, 2011.

Sato, M., Ishikawa, T., Ujihara, U., Yoshida, S., Fujita, M., Mochizuki, M. and Asada, A.: Displacement above the hypocenter of the 2011 Tohoku-Oki earthquake, Science, 332, p. 1395, doi:10.1126/science.1207401, 2011.

Sawai, Y., Okamura, Y., Shishikura, M., Matsumura, T., Aung, T. T., Komatsubara, J., and Fujii, Y.: Historical tsunamis recorded in deposits beneath Sendai Plain - Inundation areas of the A.D. 1611 Keicho and A.D. 869 Jogan tsunamis, Chisitsu News, 624, 34-31, 2006 (in Japanese with English abstract).

Sawai, Y., Namegaya, Y., Okamura, Y., Satake, K., and Shishikura, M.: Challenges of anticipating the 2011 Tohoku earthquake and tsunami using coastal geology, Geophys. Res. Lett., 39, L21309, doi:10.1029/2012GL053692, 2012.

Simons, M., Minson, S. E., Sladen, A., Ortega, F., Jiang, J., Owen, S. E., Meng, L., Ampuero, J.-P., Wei, S., Chu, R., Helmberger, D. V., Kanamori, H., Hetland, E., Moore, A. W., and Webb, F. H.: The 2011 magnitude 9.0 Tohoku-Oki earthquake: Mosaicking the megathrust from seconds to centuries, Science, 322, 14211425, doi:10.1126/science.1206731, 2011.

Tani, K.: Distribution of the death tolls and the death rate on the Great East Japan Earthquake, Occasional Paper of Dept. Geography, Saitama Univ., Saitama, Japan, 32, 1-26, 2012 (in Japanese).

Usami, T.: Materials for Comprehensive List of Destructive Earthquakes in Japan, Univ. of Tokyo Press, Tokyo, [416]-2001, 605 pp., 2003 (in Japanese).

Yamashita, F.: Fare of tsunamis-Transmission of Sanriku tsunami tales, Tohoku Univ. Press, Sendai, Japan, 2005 (in Japanese). 